\title{
Online e-learning and Cognitive disabilities: a systematic review
}

\author{
Pierre-Antoine Cinquin ${ }^{\mathrm{a}, \mathrm{b}}$, Pascal Guitton ${ }^{\mathrm{a}, \mathrm{b}}$, Hélène Sauzéon ${ }^{\mathrm{a}, \mathrm{b}}$ \\ ${ }^{a}$ University of Bordeaux \\ ${ }^{b}$ INRIA
}

\begin{abstract}
For decades now, as the issue of social progress has come to the fore, the drive to improve access to education has been behind the growth in research into e-learning. The current systematic literature review raised the question of the existence of studies addressing the specific needs of persons with cognitive impairments. Indeed, e-learning is expected to be one of the critical tools for improving access to education and ultimately aiding social inclusion. The systematic literature review was performed through a four-step process including an exhaustive search of scientific literature databases, the selection of studies through exclusion and inclusion criteria, and literature analysis and synthesis. The main results are: 1) a lack of e-learning studies addressing the issue of accessibility for people with cognitive impairments $(\mathrm{N}=29)$ with a purpose dominated by design guidelines rather than effectiveness assessment; 2) a weak inclusion of accessibility standards $(\mathrm{N}=5)$ and 3$)$ a weak inclusion of special education findings $(\mathrm{N}=3)$, with a focus on specific neuropsychological disorders or syndromes (dyslexia, ADHD, etc.) rather than on impairments of cognitive function (attention, memory, etc.) as promoted by the International Classification of Functioning (World Health Organization, 2001); 4) the identification of five families of accessibility function (adaptive systems, game elements, accessible content, virtual agents and accessible interfaces or environments) and their dependency with activity-domain of learning. Results are discussed in terms of both design and assessment recommendations, promoting a multi-disciplinary approach combining educational sciences, cognitive sciences and computer sci-
\end{abstract}


ence to develop more accessible e-learning systems.

Keywords: Distance education and telelearning; evaluation of CAL systems; lifelong learning

\section{Introduction}

There are more than one billion persons with disabilities (PWDs) in the world (World Health Organization, 2011). Although the situation has evolved, notably through political decisions aimed at combating discrimination, there are still many areas where the opportunities for persons with disabilities lag behind those for society as a whole, as demonstrated by WHO reports. It is particularly the case for education: the representation of PWDs in education decreases drastically from primary school to higher education, leading to a lower level of qualifications. This situation is one of the causes of an adverse social consequence in the professional world where the unemployment rate for PWDs is much higher than the overall average (World Health Organization, 2011). It is even more important for persons with intellectual deficiencies or cognitive impairments because they are the least likely to be engaged in school or work. Therefore, the access barriers to learning opportunities reinforce the social exclusion of PWDs, as denounced by the CRPD ratified by 177 countries (Convention of Rights of People with Disability, (UN General Assembly, 2007))

Advances in computer-based education are seen as an effective way of remedying this situation by providing assistance and compensation for learners with specific needs. Indeed, there has been a real revolution in computer-based approaches to education, driven by the explosive growth in Massive Open Online Courses (MOOCs): starting from 0 in 2011, at the end of 2017 there were more than 81 million registered users around the world 1 Such online e-learning systems radically change the way people approach learning and training. They offer access to learning content to everyone, regardless of where the learners

\footnotetext{
${ }^{1}$ https://www.class-central.com/report/mooc-stats-2017/
} 
are, and make these learners more active across their lifespan by allowing them to choose how, when and where to study. Since these platforms are available around the clock, learners can progress through the course at their own pace, reviewing concepts that have not been fully grasped and skipping those that have. These systems are also compatible with life-long training, allowing people to gain new skills and knowledge in order to adapt to an ever-changing job market. These factors provide great opportunities for creating learning environments which are beneficial to PWDs, notably those with cognitive impairments and limited learning activities, as they may offer the flexibility to adapt their training program to meet their specific needs.

Schelly et al. (2011) have shown that a growing number of students are reporting specific learning disabilities, attention deficit and hyperactivity disorders, or mental/ emotional disabilities. Such disabilities are encountered in numerous developmental (autism, epilepsy, attention disorders and hyperactivity, psychiatric diseases, etc.) or acquired (traumatic brain injury, stroke, tumor, etc.) neuropsychological disorders and can appear when aging (Craik \& Salthouse, 2011). Although these impairments are common, they are often referred to as invisible disabilities because they are generally not apparent or well understood outside medical or specialized environments.

These two observations raise a question: are online e-learning systems sufficiently accessible to people with cognitive impairments, and do such people benefit from the use of these technologies? The purpose of this article is to explore this question and thus to contribute to the field by reviewing the current state of research into the accessibility of online e-learning that supports individuals with cognitive disabilities.

\section{ICF Framework and cognitive impairments}

In this paper, we based our work on a functional view of disability following the biopsychosocial framework proposed by the International Classification of Functioning, Disability and Health, which is backed by the WHO and is widely 
used by disability experts (World Health Organization, 2001).

Firstly, this framework depicts disability as the negative outcome from a person's interaction with their social and physical environments. This emphasizes the role of environmental factors in creating disability and thus in rehabilitating PWDs through the use of accessibility supports provided in all environments (social, physical and digital).

Secondly, due to individual variability within a single medical condition as well as across medical conditions, the ICF defines disability using three functional components (Figure 1): body function impairments/deficiencies, activity limitations and social participation restrictions. Each component refers to a specific classification. Body functions (related to body structures) cover a range of eight categories from sensory and pain functions to neuromusculoskeletal and movement-related functions. One of these categories is the mental functions including two main subcategories as follows: global mental functions (awareness, intellectual functioning, executive functioning, orientation, personality, etc.) and specific mental functions (selective attention, memory, learning, language, calculation, praxis, etc.). Cognitive impairments refer to impairments of mental functions, and they are thus either global (e.g., intellectual deficiencies or executive disorders, etc.) or selective (e.g., dysphasia, amnesia, apraxia, etc.). Activities refer to all the activities performed by an individual in everyday life and they include seven subcategories including Learning and Applying knowledge. Social participation refers to roles of an individual related to social and civic life (education, places of work and employment, home, family, etc.).

Thirdly, the ICF stresses the bidirectional relationships between the three components of disability. If limited activities and restricted social participation are basically the consequences of the impairment of body functions, they are also the cause of functional impairments. Hence, the more an individual is prevented from taking a social role, the more he or she is prevented from having opportunities to learn and to engage in activities related to this social role, and the more body functions related to these activities remain inoperative or deteriorate through non-use. 
Figure 1: Representation of the ICF with exemples

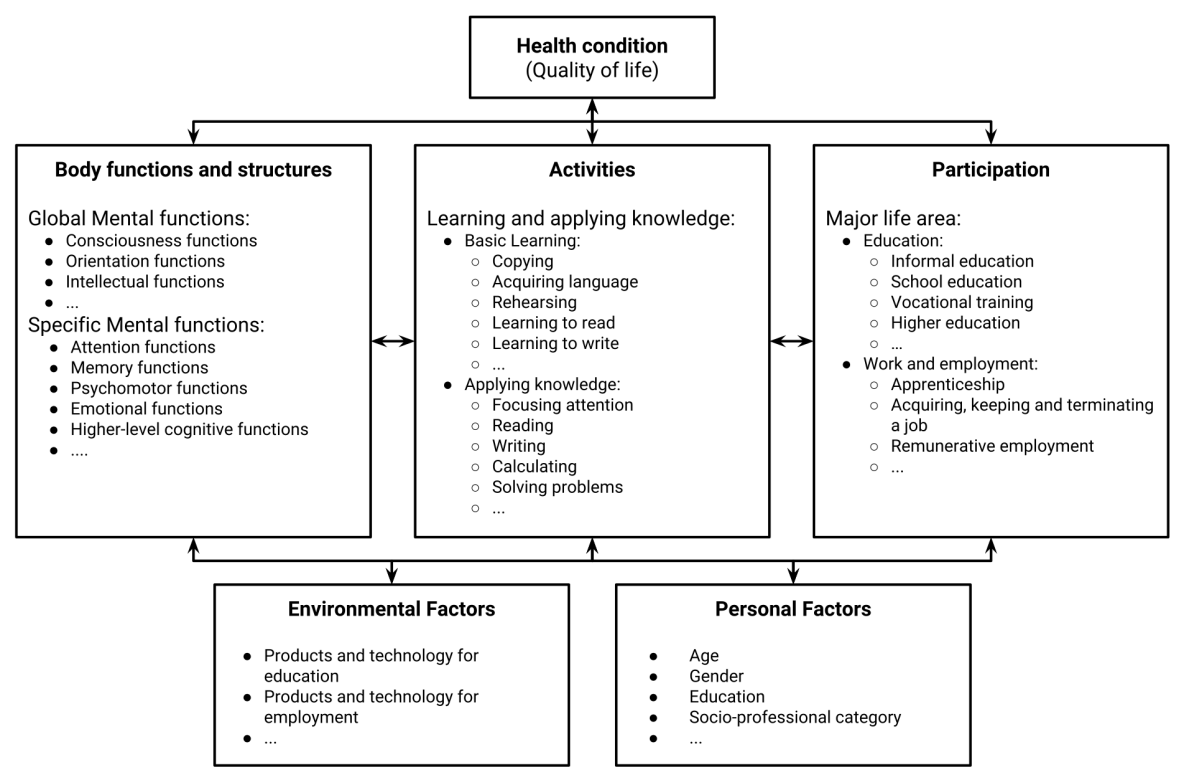

The advantage of the ICF as a universal framework is that it disregards medical conditions to focus on three components of disability. The functional view of impairments is a leverage effect on mutualizing environmental supports within the same functional impairments despite different medical conditions. For instance, reminders are effective memory supports for persons with memory impairments, irrespective of medical conditions (epilepsy, brain traumatic injuries, Alzheimer's disease, schizophrenia, etc.).

In the domain of education, global and specific cognitive impairments are widely documented as strongly affecting learning activities and are thus the principal cause of school exclusion. Global cognitive impairments severely impact all the activities related to learning while specific impairments often selectively impact learning activities. In both cases, learning limitations have negative outcomes on the school career as well as the achieved level of professional qualification. Hence, this creates the necessity to develop research into accessible learning environments for people with cognitive impairments, whilst taking into account the specificity of the growing phenomenon of e-learning. 


\section{Related Work}

In this section, as a rationale of our systematic review, we present prior literature reviews related to our research question with a focus on systematic reviews. Most of the previous literature reviews we retrieved do not focus on the accessibility of online e-learning platforms, but rather on the use of assistive technologies in all learning situations.

In a review of 118 articles from education technology journals, Istenic Starcic \& Bagon (2014) showed that the field of inclusion of people with special needs has experienced significant growth since 2000. The majority of the studies they analyzed investigated mainly the use of technology-supported learning with regard to a particular disability group, and only a few recent papers have addressed universal design. In contrast, Liu, Wu \& Chen (2013) analyzed the research trends relative to the use of learning technology in special education. They found that the most commonly used technologies in that context are computer-based ones (e.g., web-based mentoring, use of laptops and computerbased learning games). They observed that technology is mostly commonly used to help students with intellectual deficiencies to acquire basic academic knowledge, displaying a will to investigate the benefits of such technology for this particular population and focusing on evaluating the effectiveness of learning technologies through experimental studies. In the same vein, there have been reviews exploring the potential benefits of technology-based interventions for students with autism spectrum disorder (Knight, McKissick \& Saunders, 2013) or limited learning capabilities (Perelmutter, McGregor \& Gordon, 2017). As shown by Liu et al. (2013), all these different literature reviews show a general research trend oriented towards specific disorder-related disabilities (Learning Disabilities, Autism Spectrum Disorder, Attention Deficit Disorder, etc.). However, this approach is limited in its inclusiveness, as studies tend to examine the use of one specific technology for one specific medical condition. As cognitive impairments are encountered in numerous developmental and acquired neuropsy-

chological syndromes, the classification of assistive technologies by cognitive 
functions allows better prescription according to a profile of cognitive deficits. For instance, Gillespie, Best \& O'Neill (2012) used the ICF to classify assistive technologies for daily living activities and showed the effectiveness of such a classification to understand the relationship between technology and assisted cognitive functions.

Some studies have tried to overcome this situation by aiming at specific learning activities. Yet, they still focus on specific limitations of learning activities. For instance, Khowaja \& Salim (2013) carried out a review of computer-based intervention for reading comprehension of children with autism. They found 11 articles and showed that it was difficult to evaluate the benefits of these systems due to the heterogeneity of participants, although the studies show mostly positive results. This lack of evidence of effectiveness is also found in PetersonKarlan (2011) whose literature review focused on technology to support writing for students with learning and academic difficulties. The overall research trend elicited by these different studies seems to go towards the validation of existing technologies (e.g., word processing, speech recognition) used to overcome specific learning difficulties. Thus, it seems that there is a lack of studies which investigate the design and evaluation of accessibility solutions. This is why we will focus on e-learning as a whole, rather than on a specific technology. Additionally, the literature reviews presented do not really focus on the theoretical background related to special education (e.g., Universal design for learning, Rose \& Meyer (2002)) or on the accessibility standards (e.g., W3C guidelines, Web Accessibility Initiative (2018)) that lead to the choice of a particular technology, which makes research into accessibility for e-learning inconsistent.

Finally, despite the fact that the use of online e-learning systems has grown considerably over recent years, few studies investigate their accessibility for persons with cognitive impairments. In this online context, and specifically for MOOCs, Sanchez-Gordon \& Luján-Mora (2017) showed that the majority of studies were published after 2013, underlining the fact that the accessibility of these platforms is a very recent preoccupation. They also showed that most of these studies focused on sensory-impaired learners and rarely take into ac- 
count cognitive impairments. An interesting shift towards user-centered design strategies for MOOCs can be found in two chapters by Mendoza-Gonzalez (2016) (respectively by Sanchez-Gordon \& Luján-Mora (2016); González \& Rodríguez (2016)). The former promoted a three-layer architecture to adapt the content of the course to the learner's preferences, needs and competences following a set of predefined adaptation rules. The latter promoted semi-transparent layers in front of the actual MOOC interface to assist cognitive-impaired learners by indicating to them how to interact with the different elements in the interface using simple phrases and explicit interaction. However, it is noteworthy that the proposals put forward do not use a participatory design process and are basically self-made recommendations without empirical assessment. Consequently, these contributions are significant but not sufficiently underpinned by all the findings from research studies already performed in the field of accessible e-learning.

\section{Questions}

Using a systematic literature search procedure, our goal is to explore the theoretical and applied aspects of accessibility of e-learning literature and describe the nature of the existing research activities with a focus on studies geared to individuals with cognitive impairments. The overview of the field will be addressed in terms of factual information through four sets of research questions in order to document the domain activity, the background scaffolding (accessibility standards and theoretical frameworks) and the research outcomes:

RQ1. Domain characterization: Is there existing literature that deals with accessibility of online e-learning systems for people with cognitive impairments? Who are the targeted persons? Which journals and conferences have published them? How has the field evolved? What are the study purposes?

RQ2. Standards shoring: Do the selected studies make explicit reference to accessibility standards? What are those references? How many times do they appear? How has usage progressed over time? 
RQ3. Theoretical rationale: Do the selected studies make explicit reference to special education frameworks? What are those references? How many times do they appear? What changes in usage patterns have been observed over time?

RQ4. Main outcomes: What types of accessibility solutions are offered? What are the findings in terms of evaluation? What functions do they support, and is there a link between functionalities and specific learning functions?

\section{Survey Methodology}

The methodology used was a systematic literature review according to Prisma international standards (Moher, Liberati, Tetzlaff \& Altman, 2010). Our objective was to identify a set of relevant studies in the field of accessible online e-learning systems for persons with cognitive impairment and to provide an analysis of the results of these studies. To do this, we conducted a four-step method depicted below (a flowchart of the paper selection process appears in Figure 22). As a result of the paper selection process, 29 studies were included from a set of 1816 studies.

\subsection{Identification of Studies}

The Scopus, Education Resources Information Center (ERIC), ScienceDirect, ACM, IEEE Xplore, SpringerLink, EBSCOhost, Taylor \& Francis and Wiley Online Library databases were searched on September 26, 2017. This selection of databases was informed by the multidisciplinary nature of the topic. For each of them, we used the same search string: online AND (e-learning OR MOOC OR serious game) AND (learning disabilities OR intellectual deficiency OR mental retardation OR psychiatric illness OR emotional disorders OR autis* OR attention deficit).

\subsection{Inclusion and Exclusion Criteria}

The choice of exclusion or inclusion of papers was made by the authors according to specific criteria described hereafter. The great heterogeneity of 
Figure 2: Systematic review flow diagram process

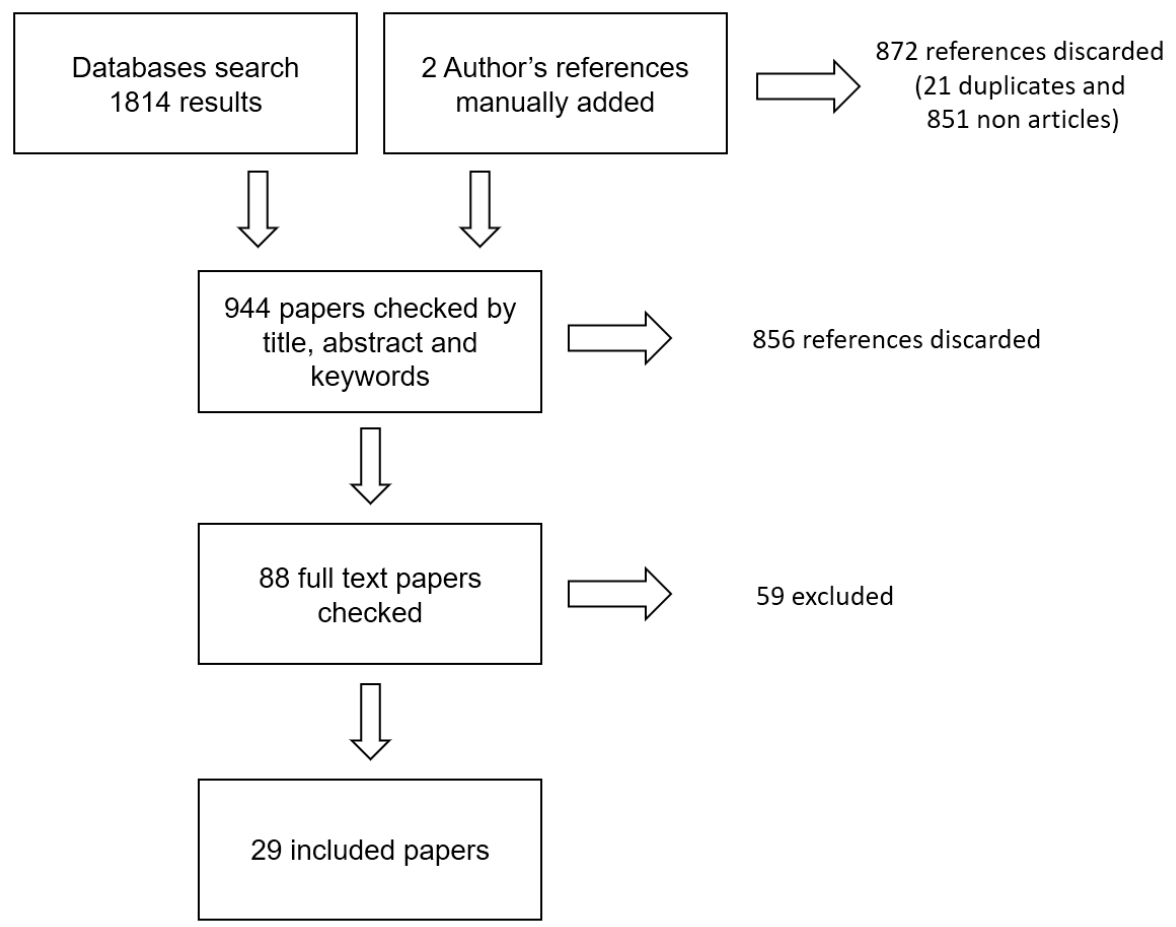

the approaches described in the studies retrieved made the selection processes essentially subjective. In cases that were not clear-cut, the authors discussed the eligibility of the criteria for the specific study until an agreement was reached. The criteria rules applied are described below.

Only studies that focused on online e-learning accessibility for individuals with cognitive impairment were included in the review. No publication period nor participant age limitations were specified. Following Clark \& Mayer (2016), we defined e-learning as instruction delivered via a digital device intended to support learning. As we wanted to focus on online e-learning, we only included studies that explicitly refer to client/server architecture such as the web. To be as descriptive as possible, we only included studies that proposed guidelines or a framework, and those with a purpose of intervention instead of instruction if they explicitly expected a possible transfer for learning. Finally, we only 
included studies that explicitly refer to people with cognitive impairments exclusively (for instance, studies focusing on people with attention disorders) or people with cognitive impairments along with other impairments (studies not focusing on a specific disability but considering cognitive impairments).

\subsection{Study Selection}

The first searches yielded 1814 results, to which we added 2 personal references (Morales-Villaverde, Caro, Gotfrid \& Kurniawan (2016); Benmarrakchi, El Kafi \& Elhore (2016)). We first filtered out references that were not peerreviewed scientific articles (book chapters, summaries of proceedings) as well as non-English language articles and duplicates. The titles, abstracts and keywords of the remaining 944 articles were exhaustively reviewed against the inclusion and exclusion criteria. The full text of the remaining 88 articles was retrieved and reviewed. Of those, we excluded 59 articles because they did not meet the inclusion criteria. A total of 29 articles remained for this review.

\subsection{Data Extraction}

During the final step, the following data was extracted from the full paper version of the studies retrieved: authorship, year of publication, publication type, persons and disabilities addressed (i.e., type of impairments regarding cognitive functions or cognitive capabilities according to the ICF classification), proposed solution, educational goal, accessibility references, specialized education references, design method, evaluation design and results.

\subsection{Quality Assessment}

The quality of the studies was rated using the SIGN (Harbour \& Miller. 2001) ratings of levels of evidence. This evaluation method proposes an estimate of the strength of available evidence provided by a study, based on the methodological design and the evaluation of possible biases. It contains eight grades of recommendation as follows: 
- 1++: High quality meta-analyses, high quality systematic reviews of clinical trials with very little risk of bias.

- 1+: Well-conducted meta-analyses, systematic review of controlled studies or well-conducted studies with low risk of bias.

- 1- : Meta-analyses, systematic reviews of experimental studies with high risk of bias.

- 2++: High quality systematic reviews of cohort or case and controlled studies; cohort or case and control studies with very low risk of bias and high probability of establishing a causal relationship.

- 2+: Well-conducted cohort or case and controlled studies with low risk of bias and moderate probability of establishing a causal relationship.

- 2-: Cohort or case and controlled studies with high risk of bias and significant risk that the relationship is not causal.

- 3: Non-analytical studies, such as case reports and case series.

- 4: Expert opinion.

Given the rejection of literature reviews $(\mathrm{N}=9)$ during our selection process, the best possible grade for the studies retrieved was $2+$.

The selected studies rely principally on expert opinions and on small-sample or single subject experimental designs, thus most of them were rated 3 or 4 (see Table 5). Two complementary explanations can be advanced for this result. Firstly, the newness of this research domain could account for the fact that most of the studies are pilot studies which focus more on design objectives than evidence strength. This means that evidence-based studies could be expected to be published within the next few years. Secondly, due to the variation in the functional needs and preferences of persons with disabilities, case study design can be considered to be a more appropriate way of illustrating the complexities of the different situations that occur when they use an e-learning system (Rossman \& Rallis, 2003). 


\section{Results}

The next step of the review was to perform a within-study and between-study analysis from the final corpus of selected articles to identify characteristics and answer the research questions defined for our review purpose. A summary of the main findings and the principal characteristics of the reviewed studies are provided in Table 5. For ease of reading, we have assigned an ID number to each study, so that the reader can refer to this table for further information.

\subsection{Domain characterization: Is there existing literature on the subject of acces-} sibility of online e-learning systems for people with cognitive impairment? Who are the targeted people? Which journals and conferences published them? How has the field evolved? What are the study purposes? (RQ1)

As we have already stated, the final literature corpus was composed of 29 relevant studies answering the first part of RQ1 about existing literature on the subject.

Out of the 29 studies, 19 of them targeted a specific age group, 8 targeted children or persons below the age of 18 (27.5\%) and 11 targeted adults $(38 \%)$. Two studies $(7 \%)$ were aimed at special education teachers while the rest $(27.5 \%)$ were more general and did not specify a target age group. This indicated a rather homogeneous distribution of the studies regarding the age of the targeted participants, even though a significant proportion of them is not specially addressed to a specific age group. With regard to the classification of disabilities proposed by the ICF, 17 studies focused on a specific cognitive impairment, 8 did not specify any particular impairment and 2 were geared to persons without disability (special education teachers). In contrast, 10 directly referred to medical conditions (etiologies, diseases or syndromes).

The included consisted of 12 from journal articles and 17 from conference papers. A total of 11 journals and 15 conferences published the studies retrieved, with 1 journal and 2 conferences represented twice (Tables 1 and 2 show a detailed list of journals and conferences with a reference to the corresponding 
studies' ID). These different sources are mainly related to the emerging interdisciplinary fields such as computers and education or computers and disability.

Table 1: Journals retrieved and their corresponding studies

\begin{tabular}{|l|l|r|}
\hline ID & Journal Title & Study ID \\
\hline J1 & Education and Information Technologies & 8,24 \\
\hline J2 & Computers in Human Behavior & 1 \\
\hline J3 & British Journal of Educational Technology & 3 \\
\hline J4 & Computers \& Education & 16 \\
\hline J5 & International Journal on E-Learning & 18 \\
\hline J6 & Journal of Autism and Developmental Disorders & 27 \\
\hline J7 & Universal Access in the Information Society & 6 \\
\hline J8 & Computers in the Schools & 25 \\
\hline J9 & Journal of Teaching in Social Work & 7 \\
\hline J10 & Cognitive Processing & 21 \\
\hline J11 & Open Learning: The Journal of Open, Distance and e- \\
& Learning & \\
\hline
\end{tabular}

Although e-learning is a topic which has existed for a long time Clark \& Mayer, 2016), the first paper we retrieved was published in 2002. Moreover, more than $50 \%$ of the retrieved studies were published in the last 5 years, showing that the field is currently growing. Nevertheless, none of them were related to MOOCs.

To assess the study purpose of the e-learning accessibility field, we classified all the included studies into four categories of study type that they could be a part of, exclusively or otherwise. The four categories were as follows:

(1) Studies $(\mathrm{N}=14)$ reviewing existing accessibility or special education guidelines or frameworks (tagged GA for Guidelines Acknowledgment);

(2) Studies (N=9) proposing recommendations or criteria for accessibility (tagged NGE for New Guideline Establishment);

(3) Studies $(\mathrm{N}=19)$ designing new e-learning solutions without user evaluation (tagged NES for New e-learning Solution);

(4) Studies $(\mathrm{N}=17)$ stressing the evaluation of a solution or use of guidelines (tagged GSA for Guideline or Solution Assessment).

Although these categories provide a heuristic view of the state-of-the-art, it is noteworthy that the heterogeneity of the studies approaches cannot be 
Table 2: Conferences retrieved and their corresponding studies

\begin{tabular}{|c|c|c|}
\hline ID & Conference Name & Study ID \\
\hline C1 & $\begin{array}{l}\text { International Conference on Computers for Handicapped } \\
\text { Persons: Computers Helping People with Special Needs }\end{array}$ & 4,19 \\
\hline C2 & $\begin{array}{l}\text { International Visual Informatics Conference 2011: Visual In- } \\
\text { formatics: Sustaining Research and Innovations }\end{array}$ & 23 \\
\hline C3 & $\begin{array}{l}\text { International Conference on Universal Access in Human- } \\
\text { Computer Interaction: Universal Access in Human- } \\
\text { Computer Interaction. Applications and Services }\end{array}$ & 9 \\
\hline $\mathrm{C4}$ & $\begin{array}{l}\text { International Conference on Advanced Computing Technolo- } \\
\text { gies and Applications (ICACTA) }\end{array}$ & 20 \\
\hline C5 & $\begin{array}{l}\text { 27th ACM Conference on Hypertext and Social Media (HT } \\
\text { 2016) }\end{array}$ & 17 \\
\hline C6 & $\begin{array}{l}\text { 1st International Conference on Networked Digital Technolo- } \\
\text { gies }\end{array}$ & 13 \\
\hline C7 & $\begin{array}{l}\text { The 8th IEEE International Conference on Advanced Learn- } \\
\text { ing Technologies, ICALT } 2008\end{array}$ & 14 \\
\hline C8 & International Conference on Games and Learning Alliance & 15 \\
\hline C9 & $\begin{array}{l}\text { International Educational Technology Conference, IETC } \\
2014\end{array}$ & 10 \\
\hline $\mathbf{C 1 0}$ & W4A '16: Proceedings of the 13th Web for All Conference & 22 \\
\hline C11 & $\begin{array}{l}\text { 5th International Conference on Software Development and } \\
\text { Technologies for Enhancing Accessibility and Fighting Info- } \\
\text { exclusion, DSAI } 2013\end{array}$ & 5,26 \\
\hline $\mathbf{C 1 2}$ & 2nd World Conference on Educational Technology Research & 2 \\
\hline C13 & $\begin{array}{l}\text { Proceedings of the 7th European Conference on e-Learning, } \\
\text { ECEL } 2008\end{array}$ & 12 \\
\hline $\mathbf{C 1 4}$ & ASSETS 2016 & 28 \\
\hline C15 & International Conference on Engineering \& MIS & 29 \\
\hline
\end{tabular}


Figure 3: Number of studies and the purpose of those studies from 2002 to 2017

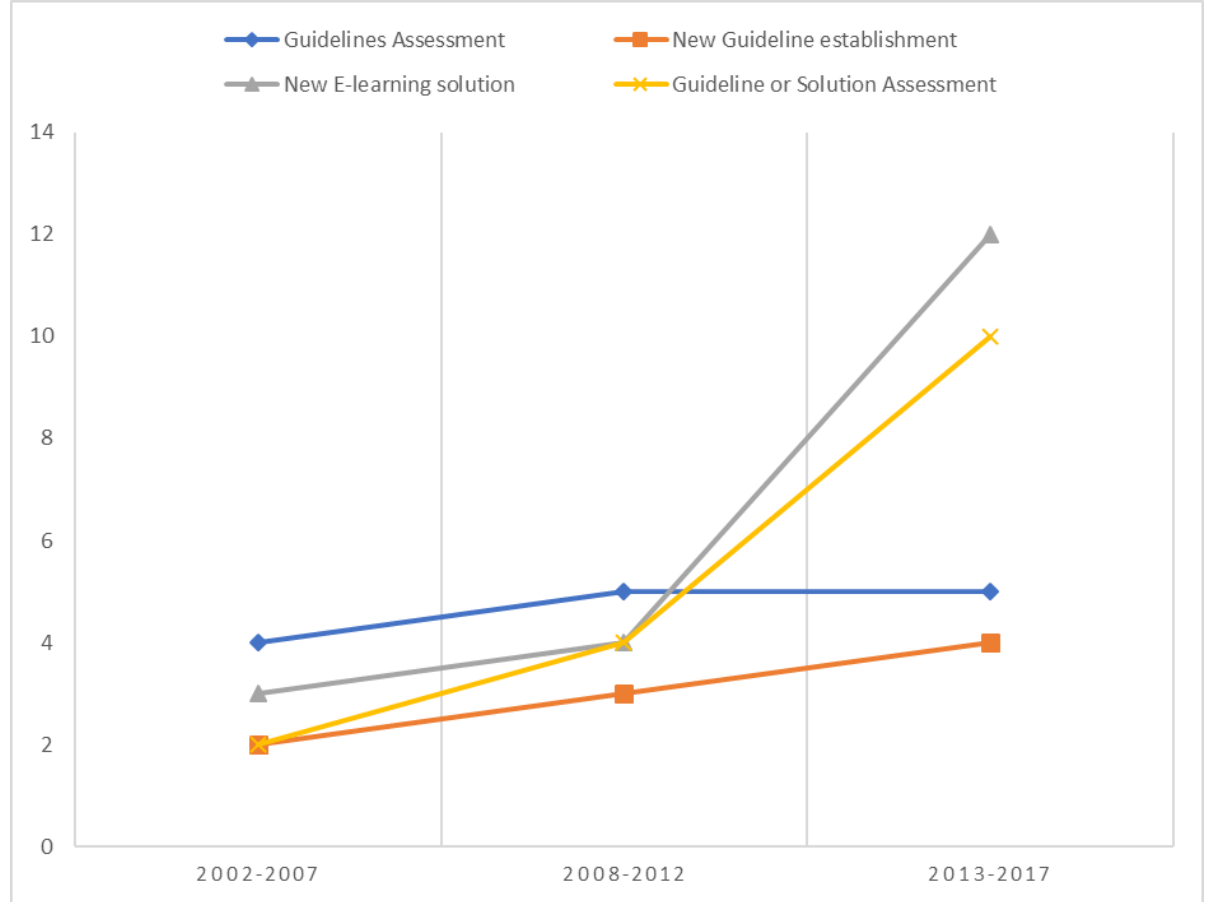

described without an in-depth depiction of them. We will deal with all the details in the next sections.

Among the 16 studies including an evaluation of a system (already in existence or presented in the study), 4 were expert opinions or student observations (Studies ID: 1, 7, 14, 23), 2 were an accessibility evaluation of an existing system through pre-existing guidelines $(5,6), 6$ were case-studies $(9,13,21,24,26,28)$, 3 were within-subject studies $(3,16,22)$ and 1 was a between-group study (8).

Figure 3 illustrates changes in the scientific objectives of the retrieved studies over time. As we can see, initial objectives were the exploration and introduction of accessibility guidelines, then came the proposals for functionalities and systems and finally the evaluation of accessibility functionalities and systems.

The next two questions will present the background and rationale of the studies, following two metrics allowing the strength of research to be evaluated: the number of accessibility standards references (RQ2) and the number of special 
education frameworks references (RQ3).

6.2. Standards shoring: Do the selected studies make explicit reference to accessibility standards? What are those references? How many times do they appear? How does usage change over time? (RQ2)

There are few references to accessibility standards in the studies retrieved. They can be divided into two groups of recommendations:

(1) Universal recommendations related to accessibility working groups. In this first group, we found the different recommendations made by the Web Accessibility Initiative (WAI) such as the Web Content Accessibility Guidelines (WCAG), the Authoring Tools Accessibility Guidelines (ATAG) or the User Agent Accessibility Guidelines (UAAG) which are mentioned 5 times, and the US government's rehabilitation act (Section 508) which was mentioned twice.

(2) Specific recommendations derived from research studies. This second group gathered together literature reviews on autistic spectrum disorders (studies ID: 15, 17 and 27), dyslexia (studies ID: 2, 20 and 22), Acquired Brain Injury (study ID: 16) as well as the Web Accessibility Guidelines for People with cognitive disabilities from Friedman \& Bryen (2007) (study ID: 13).

It is noteworthy that these accessibility recommendations are rarely described and that their use in the context of the study is rarely explained.

6.3. Theoretical rationale: Do the selected studies make explicit reference to special education frameworks? What are those references? How many times do they appear? How have usage patterns changed over time? (RQ3)

We found a total of 5 references to special education frameworks distributed in only 3 studies as described hereafter:

- Universal Design for Learning (UDL)(Rose \& Meyer (2002); studies ID: $5,6,21)$ is an inclusive framework based on an extension of the Universal Design principles to the learning environment. Several principles 
assist teachers to develop teaching goals that address the needs of a wide range of students with or without disabilities such as providing them with multiple means of representation (e.g., by offering ways of customizing the display of information), expression (e.g., by offering multiple tools for composition) and engagement (e.g., by optimizing individual choice and autonomy through self-regulated tools). These guiding principles are mainly based on Vygotsky's work on the Zone of Proximal Development (Vygotsky, 1978) and neuroscience research.

- AccessForAll Meta-data (ISO/IEC 24751 IMS Global Learning Consortium (2004); studies ID 5, 6), developed by the IMS Global Learning Consortium, gathers specifications to facilitate the identification of resources which match a user's preferences and needs for alternative presentations of resources, alternative methods of controlling them or alternative equivalents to the resources.

- IMS Guidelines for Developing Accessible Learning (Barstow \& Rothberg (2004); studies ID 5, 6 and 7), also developed by the IMS Global Learning Consortium, provides a framework for the distributed learning community assessing the accessibility solutions that currently exist, how to implement them and why they should be utilized, as well as the future development and innovation needed in educational technologies to ensure accessibility for all.

- Universal Design for instruction (UDI) (Burgstahler (2009), study ID: 21 ) intends to apply the Universal Design principles to the overall design of instruction and to specific instructional materials, facilities and strategies. This is a more general framework that can encompass different types of instruction that employ principles of UD (e.g., UDL apply UD to curriculum), organized into eight performance indicator categories: class climate, interaction, physical environments and products, delivery methods, information resources and technology, feedback, assessment and accommodation. 
- Universal Instructional Design (Higbee \& Goff (2008); study ID: 21), along the same lines as UDI, this provides a set of guidelines for accessible learning environments and course elements, but specifically focused on post-secondary settings.

Although there is an obvious lack of references to specialized education frameworks, we still found references to more general education principles such as Kolb's learning cycle (Kolb, 1999), Self-regulated Learning theories (Zimmerman, 2013) or Keefe's learning style theory (Keefe, 1988), in 4 reviewed studies (Studies ID: 8, 17, 18 and 27).

RQ2 and RQ3 stressed that the reviewed studies exhibited some shortcomings regarding the respect of standards and theoretical frameworks related to both accessibility and special education. Indeed, the studies without referencing tend to present their own guidelines based on their analysis of literature or of their own observations and interviews with stakeholders.

6.4. Main outcomes: What types of accessibility solutions are offered? What are the findings in terms of evaluation? What functions do they support, and is there a link between functionalities and specific learning functions? (RQ4)

Eighteen articles present a specific e-learning system or accessibility features designed for persons with cognitive disabilities. Assistive technology can usually be classified using the ISO 9999 (International Organization for Standardization, 2016) classification. Unfortunately, most of the solutions presented in the articles do not really fit into the different categories of the detailed classification as they try to provide generalized assistance to a generic or specific learning goal rather than assistance toward a particular cognitive function. We then introduced a classification following the tools proposed:

(1) Adaptive systems: systems where the interface or the content can be adapted (automatically or manually) for a specific user. 
(2) Game elements: systems that use game element (e.g., gamification tools as badges, narrative, level) or serious games.

(3) Accessible content: tools that provide accessible content for education or rehabilitation of specific skills.

(4) Virtual Agent: use of virtual agent to provide support to the learner.

(5) Accessible interface or environment: systems that present interfaces specifically designed for person with disabilities.

The following sections present in greater detail each of the accessibility solutions for each category. To simplify the referencing, an ID number has been attributed to each detailed study (Table 5).

\subsubsection{Adaptive systems}

[1] Alghabban, Salama \& Altalhi (2017) developed a cloud-based mobile learning tool for students with dyslexia using multimodal interfaces which enabled a manual customization of the interface and multiple modalities of input and output as defined by Kurkovsky (2009). They conducted a user needs analysis through a literature review, interviews and questionnaires with special educational teachers, dyslexic students and their parents, and offered an architecture with three components: a mobile client, a public network and a cloud environment to provide the content. They also presented an evaluation using a pretest-posttest design study showing an increase in reading skills after three months of use. Unfortunately, the design methodology is not presented (e.g., they do not provide their sample, nor the test used to measure reading skills) leading to difficulties in evaluating the efficacy of the tool proposed.

[2] Andruseac, Rotariu, Rotariu \& Costin (2013) proposed an online learning platform for personalized therapy and online monitoring of children with speech and cognitive disorders (mainly dyslexia). The platform consisted of two components: a) an application for patient management allowing speech therapists, patients and administrative staff to communicate and organize therapy sessions and $b$ ) a piece of interactive multimedia software (named Recovery Module) for the rehabilitation process of patients with dyslexia. The software featured four 
components to train them to practice reading and understanding through both verbal and written answers, as well as to practice word pronunciation. Each of the exercises had different levels of difficulty and provided personalized feedback, and patients had various choices of interaction to answer the questions (talk, write, choose from a list of images or words, etc.). They did not conduct any evaluation.

[9] Debevc, Verlič, Kosec \& Stjepanovič (2007) proposed a mobile application designed to support a remote engineering application for people with special needs. The system consists of a wooden model of a house with micro-controlled devices (such as lamps, ventilation, doors, etc.) that can be remotely controlled via a mobile interface. The learning goal presented is for the learner to be acquainted with ways to use the micro-controlled system and methods to design the user interface. However, even though they mentioned cognitive impairments, participants of the experimental study were either visually impaired or hard of hearing persons.

[17] García, De Bra, Stash, Fletcher, Fabri \& Pechenizkiy (2016) described an adaptive web-based application based on a Content Management System (WordPres: $\AA^{2}$ ) and an adaptation library, intended to give students with autistic spectrum disorders a taste of how higher education works and how to cope with the university environment. Based on the user history and profile, the system adapted the content and its presentation. The evaluation was mostly technical as the project focused on performance. The authors conducted a study regarding the execution time of the system. Results showed that web pages were quick enough to load, an important quality given the possible impatience of the users.

[19] Petz \& Miesenberger (2006) presented a project (ECDL without barriers) whose aim was to develop a web-based e-learning multimedia player with possible interface adaptations for persons with disabilities and persons with agerelated disabilities, including cognitive impairments. The system provided an HTML version to be used with a screen reader, easy to read texts, font man-

\footnotetext{
${ }^{2}$ https://wordpress.com/
} 
agement (size, color and contrast with the background) and keyboard shortcuts to simplify orientation and navigation. No participant study was presented in the paper.

[20] Pirani \& Sasikumar (2015) proposed an assistive learning environment for students with learning disabilities. Following visits to special institutions and hospitals as well as interviews with special education teachers, their system consisted of a web-based environment including a content repository, learner profile storage including learner information and goals, a knowledge transformation catalogue identifying the adaptation needed for each learner, and in addition a monitoring module providing teachers and parents with information on learner progression. Finally, an assistive learning engine was responsible for adapting the content, the pedagogy and the presentation. No participant study was presented in the paper.

\subsubsection{Game elements}

[3] Bakker, van den Heuvel-Panhuizen \& Robitzsch (2016) evaluated the effects of an intervention using web-based mathematics computer games on the multiplicative reasoning ability of special education students. Sixteen mini games were proposed during two 10-week periods, accompanied by lessons and discussions in a classroom environment. The evaluation methodology was a pretest-posttest control-group design with 81 special primary education students with the control group playing non-multiplicative games. Results showed that students using multiplicative mini-games obtained significantly higher learning outcomes than the control group in declarative knowledge in mathematics, and equal results for procedural and conceptual knowledge.

[4] Serious games were used to promote social inclusion of persons with learning difficulties in Battersby, Kelly, Brown \& Powell (2002). An e-learning portal website aggregated mini-games that taught horticultural skills to encourage people with learning disabilities to pursue and engage in professional training. This article is a presentation of a project and thus it did not present any evaluation.

[15] Hulusic \& Pistoljevic (2015) presented an interactive eBook specially 
designed for children with autistic spectrum disorders. Based on web technology, the authors proposed additional auditory-visual stimulation related to the text and comprehension assessments through multi-layered questions. The educational goals presented were to teach new vocabulary, counting, the identification of numbers and colors, and to respond to inference questions. No evaluation was presented.

[22] Based on the fact that teaching students with learning limitations to play chess benefits their school performance, Rello, Subirats \& Bigham (2016) developed a serious game to teach it to people with dyslexia. It consisted of nine 30 to 45 -minute lessons followed by questions based on reading comprehension, visuo-spatial attention and numerical ability. The presentation was based on previous accessibility research studies and thus ensured the readability of persons with dyslexia (fixed column widths, a black font on a cream-colored background, the Arial typeface font and a 14 point minimum font size). The design protocol relied on two pilot tests using a think aloud protocol with three adults and four children. They conducted a within-subject study with 62 participants (31 diagnosed as dyslexic) to test how people with dyslexia learn to play chess. Results showed that they spent more time learning chess theory, doing training with exercises and playing against the computer than people without dyslexia, suggesting that dyslexia might have an impact on chess performance.

[23] Iradah \& Rabiah (2011) presented a web-based cognitive rehabilitation tool (Edutism) to assist children with autistic spectrum disorders and with high-cognitive functioning. The system monitored and analyzed the students performance, and a rules-based algorithm decided the level of difficulty according to a percentage of success. A specific module allowed teachers to monitor the students' progress and provided a summary of acquired skills. To assess usability and acceptance, they conducted interviews with three special education teachers and observed five children with autism using Edutism. Findings showed that teachers agreed on the attractiveness and effectiveness of the tool and that the children enjoyed using the prototype.

[24] Sitra, Katsigiannakis, Karagiannidis \& Mavropoulou (2017) used a badge- 
based gamification strategy for an academic course through Moodl $3^{3}$ a Learning Management System. The goal of the study was to analyze the effect of badges on the engagement of students with special educational needs (such as attention deficit disorders, mild intellectual deficiencies, emotional difficulties or dyslexia). The authors interviewed five children and analyzed data from the Moodle platform. They found positive results with students perceiving the gamified version more interesting and motivating, especially in the case of a student with ADHD who was able to concentrate for much longer than usual. However, no clear impact on performance could be found.

\subsubsection{Content}

[16] Montero, López-Jaquero, Navarro \& Sánchez (2011) presented HABITAT, a tool providing 23 relearning activity patterns for people with acquired brain injuries, which consisted of a catalogue of activities and their links to cognitive relearning. The different requirements for this software tool were gathered through interviews and observations with patients and specialists. To assess acceptability, a comparison study between a traditional relearning material (paper cards) and HABITAT was conducted with 10 adults with moderate physical and cognitive impairments. The results revealed that younger persons accepted computer-based activities, and that the tool increased the patient's motivation and reduced the task completion time.

[28] Morales-Villaverde et al. (2016) presented an online learning system to help persons with developmental deficiencies acquire basic skills in order to be able to perform daily living activities. Based on a web application and intended to be used on touchscreen devices, the system offered seven basic activities (recognizing numbers, letters, money, shapes and colors) and was designed to mimic how users normally perform such activities in a more traditional rehabilitation context (i.e., during activities proposed by caregivers in a special institution). The authors conducted preliminary evaluations of a prototype through heuristic

\footnotetext{
${ }^{3}$ https://moodle.org/
} 
evaluation and user-study. Positive results suggested that their system can be helpful for persons with developmental deficiencies. The system also demonstrated good acceptability.

\subsubsection{Virtual Agent}

[8] Chatzara, Karagiannidis \& Stamatis (2016) proposed the use of an intelligent emotional agent as a virtual character with the aim of providing cognitive support to students with learning difficulties and attention disorders. The 3D agent, named Sophia, was capable of gestures, facial expressions, body movements and speech. Following the Kolb's four stages of learning model Kolb, 1999) and Aist's work on emotions relevant to learning (Aist, Kort, Reilly, Mostow, Picard et al. 2002) the agent provided customized emotional support depending on the user's behavior (a sequence of events) and user profile. They conducted a study using a between-groups comparison methodology with a group of 12 students with learning limitations and attention deficit disorders using the emotional agent and a group of 12 students (same disability profile) using an agent with a neutral behavior. Results showed that the group with the emotional agent made a greater attempt to contact the agent, obtain better results, and try again more often after a failure than the group with a neutral agent.

\subsubsection{Accessible Interface / Environment}

[13] Fryia, Wachowiak-Smolikova \& Wachowiak (2009) presented a prototype for an online course with a web-based interface targeting persons with learning difficulties or persons with autistic spectrum disorders and high cognitive functioning such as Asperger's Syndrome. Based on Friedman and Bryen's web accessibility guidelines (Friedman \& Bryen, 2007), their system was designed to simplify the different steps used in online systems such as registration, the navigation through the different lessons, the organization to fulfill the assignment or the communication with teachers through email by providing multi-step checklists. The authors conducted a pilot study with a fifteen-year-old student 
with learning difficulties who was asked to perform specific tasks within the e-learning system. They reported that the student accomplished all the tasks without any external help and reported satisfaction with the overall appearance.

[14] In the same vein, Harrison, Stockton \& Pearson (2008) designed and developed an adaptable virtual learning environment (Portland Plus VLE) for young adults with severe learning limitations and physical impairments. Needs and preferences of the targeted group were collected through learner observations and focus groups with learners and tutors, and gave rise to profiles providing specific access to the environment. Based on this information, tutors could adapt the design and functionality to each learner and thus give access to tailored learning resources. New input methods were also proposed, such as a scanning mechanism enabling the learner to use single-switch or two-switch interactions alongside the more traditional mouse interaction or touchscreen input. Qualitative feedback was taken from a sample of the target user group.

[26] Tsiopela \& Jimoyiannis (2014) presented the design and development of a web based environment supporting pre-vocational teaching for students with autism. The environment represented a school classroom where different benches offered ten tasks related to basic skills such as grouping objects (fruits, eggs, postal envelopes) by number or sorting them by size or length. A twomonth study was conducted in a public-sector special vocational high school with six students with autistic spectrum disorders, the aim of the study being the learning transfer to real life situations. Various data (e.g., log files, biofeedback signals, video records and observation notes) were collected over several sessions. The article presented preliminary results through a single-student case study. These first results supported the relevance of the virtual environment to help students with ASD to acquire pre-vocational skills.

\subsubsection{Summary of the proposed solutions}

From the overall data, it appears that the studies did not really refer to specific cognitive functions assistance (i.e., memory, attention, etc.), but rather focused on specific learning activities assistance. Consequently, we used the 
International Classification of Function (World Health Organization, 2001) to categorize the activities supported by each system. This framework enabled us to measure health and disability at both an individual level and a population level, and is an agreed international standard. To recap, the ICF focuses on functions and activities rather than etiology and medical diagnosis.

The learning activities that took place during the use of e-learning systems were classified using the ICF classification of Basic Learning and Applying Knowledge with seven activities for Basic Learning (copying, rehearsing, learning to read, learning to write, learning to calculate, acquiring basic skills, acquiring complex skills) and eight for Applying Knowledge (focusing attention, thinking, reading, writing, calculating, solving simple problems, solving complex problems, making decisions). We do not mention the non-defined subsections for reasons of clarity. Details for each study can be found on page 28 in Table 3 for Basic Learning and Table 4 for Applying Knowledge.

There are slightly more studies that focus on Basic Learning activities $(\mathrm{N}=10)$ rather than Applying Knowledge $(\mathrm{N}=8)$. The sub-section shows that only three out of seven activities are addressed for Basic Learning and five out of eight for Applying Knowledge. There were seven activities that are not addressed in the studies we retrieved: copying, rehearsing, learning to write and learning to calculate (belonging to the Basic Learning group) and thinking, writing and solving complex problems (from the Applying Knowledge group). While there were studies that specifically pointed out the difficulties encountered by persons with dyslexia, it is interesting to note than none of them proposed a solution for the writing activities.

As we wanted to investigate the choice of a particular accessibility solution, we paired the solution types to the activities supported to explore any potential relationship between them. Figure 4 shows the resulting graph.

As we can see, the most widely used solutions are game elements, which are used in four different learning activities, followed by accessible interfaces (used in three different activities) and adaptive systems which were used in two activities. Content tools and virtual agents were used only for one particular activity. On 
Table 3: Basic Learning

\begin{tabular}{|c|c|c|}
\hline ID & Authors & ICF classification \\
\hline 2 & Andruseac et al. $(2013)$ & Learn to read \\
\hline 4 & Battersby et al. (2002) & Acquiring Complex Skills \\
\hline 9 & Debevc et al. $(\overline{200 \overline{7}})$ & Acquiring Complex Skills \\
\hline 15 & Hulusic \& Pistoljevic (2015) & Learn to read \\
\hline 16 & Montero et al. $(2011)$ & Acquiring basic skills \\
\hline 17 & García et al. $(2016)$ & Acquiring complex skills \\
\hline 22 & $\overline{\text { Rello et al. }(2016)}$ & Acquiring complex skills \\
\hline 23 & Iradah \& Rabiah $(\overline{2011)}$ & Acquiring basic skills \\
\hline 26 & Tsiopela \& Jimoyiannis $(2014)$ & Acquiring basic skills \\
\hline 28 & Morales-Villaverde et al. $(\overline{2016})$ & Acquiring basic skills \\
\hline
\end{tabular}

Table 4: Applying Knowledge

\begin{tabular}{|c|c|c|}
\hline ID & Authors & ICF classification \\
\hline 1 & Alghabban et al. $(2017)$ & Reading \\
\hline 3 & Bakker et al. $(2016)$ & Calculating \\
\hline 8 & Chatzara et al. (2016) & Solving Problems \\
\hline 13 & Fryia et al. $(2009)$ & Making decisions \\
\hline 14 & Harrison et al. (2008) & Making decisions \\
\hline 19 & Petz \& Miesenberger $(2006)$ & Reading \\
\hline 20 & Pirani \& Sasikumar & Reading \\
\hline 24 & $\overline{\text { Sitra et al. }}(\overline{2017})$ & Focusing attention \\
\hline
\end{tabular}


Figure 4: Matching between solutions and learning activities

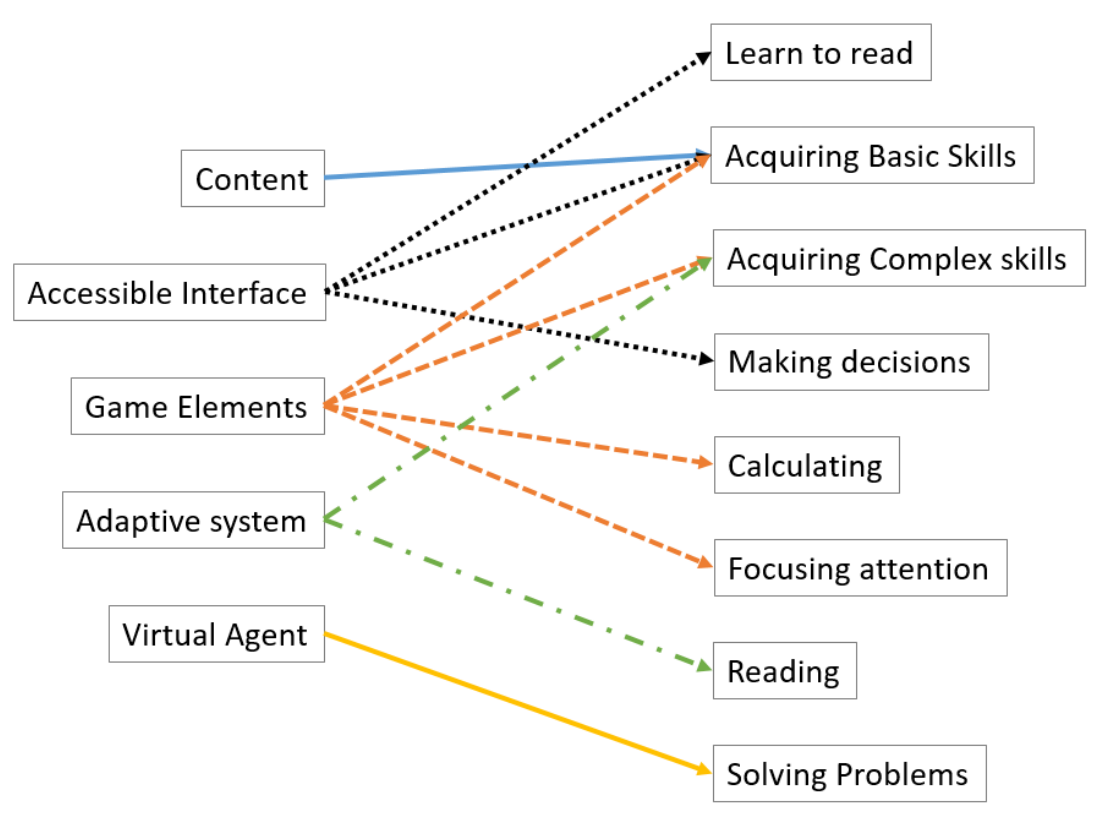

the other hand, we can see that the activities from the Basic Learning group are addressed with multiple solutions while those from the Applying Knowledge group are only addressed by a specific solution.

\section{Discussion and Recommendations}

This systematic review aimed to provide an overview of the current state of research on e-learning accessibility for persons with cognitive disabilities. The results showed a lack of use of both accessibility and special education references in the design process, and a focus on specific neuropsychological disorders or syndromes (dyslexia, ADHD, etc.) rather than cognitive function (attention, memory, etc.). The studies also exhibited a lack of effectiveness evaluation, which was mostly done through case reports involving a limited number of subjects. Indeed, the SIGN ratings showed methodology weaknesses (study design, learning measures, etc.). Although usability and acceptance are essential components for examining any benefits of a specific solution, studies are essentially 
focused on these two aspects and rarely evaluate the positive effects in terms of learning processes (acquisition, storage and progression, etc.).

As a result of this review, two categories of recommendations, that is to say solution design and evaluation, are proposed for moving forward the field of e-learning accessibility for persons with cognitive impairments.

\subsection{Design Recommendations}

Among the research perspectives for the solution design to improve the field, we have identified four priorities for future studies (i.e., sharing a common reference, developing adaptive solutions, reinforcing the learner's engagement and supporting the learner's production of content).

Sharing common references. As stressed by Scherer (2005), the use of a common reference would be a huge benefit to the accessibility community, both for researchers and practitioners alike. As an example, Gillespie et al. (2012) proposed a classification of technologies for cognition based on the ICF classification, allowing a more straightforward identification of what technology could be useful for a specific cognitive function impairment while taking into account the activity domain. Inspired by this approach, future studies should design their systems or features within a framework built around the ICF learning activities (see for instance Figure 4 on page 29p. This will allow solutions to be much more generalizable across the heterogeneity of cognitive impairments and their related disabilities, and enable the consideration of both specific and global cognitive functions. In terms of web accessibility, the recent work produced by the W3C Cognitive and Learning Disabilities Accessibility Task Force ${ }^{4}$ is an interesting approach to improve accessibility for people with cognitive impairments. Based on a user-research methodology, this work proposes a taxonomy of eight cognitive functions (e.g., attention, executive function, knowledge, language, etc.) applied to eight of the most common medical conditions (Aging-Related Cognitive Decline, Aphasia, Attention Deficit Hyperactivity Disorder, Autism,

\footnotetext{
${ }^{4}$ https://w3c.github.io/coga/user-research/
} 
etc.) and gives some global and group specific suggestions and techniques for web authors. Still in its early stages, this work does not deal with specific activities such as learning, which is planned to be addressed in a future phase where more user groups will be taken into consideration.

Investigating the use of adaptive content. The adaptive e-learning systems depicted in this study are mostly focused on the user interface or the way that learning content is presented. Future studies should also consider focusing on adaptive content following educational purpose, for instance by proposing exercises that fit learners' abilities thanks to machine learning embedded in an intelligent tutoring system (Clement, Oudeyer \& Lopes (2016); Xu, Huang, Wang \& Heales (2014)). Together with an inclusive approach such as the abilitybased design principles (Wobbrock, Kane, Gajos, Harada \& Froehlich, 2011), future solutions should rely more on learners' capabilities in order to provide the most appropriate content, based on their profile and an analysis of their results. Besides the processing of data gathered from the online activity information of platform use, it might also be interesting to explore data from additional physiological sensors (smartwatches, webcams for pupillary response, Electroencephalography, etc., see Fairclough (2008)). For instance, these systems could help to evaluate attention levels (Klimesch, Doppelmayr, Russegger, Pachinger \& Schwaiger, 1998) or cognitive load in real time (Beatty, 1982), and thus suggest possible adaptations for the interface and the content, taking into account both the inter-individual and the intra-individual variability.

Reinforcing engagement and self-determination in e-learning. Motivation has a vital role to play in learning activities and can have a huge influence on a learner's results (Stipek, 1993). Engaging the learner is a fundamental goal, especially for PWDs who tend to have a greater drop-out rate in online distance learning situations (Iniesto, McAndrew, Minocha \& Coughlan, 2017). Future studies should focus on offering solutions to reinforce the learner's commitment, based on the Self-Determination Theory (Ryan \& Deci, 2000) which has been proven beneficial in e-learning situations (Roca \& Gagné, 2008) and for acces- 
sibility (Field, Sarver \& Shaw, 2003). Thus, the evaluation of the proposed solutions should take into account the feeling of autonomy and competence, along with relatedness when the e-learning platform is built around an online community, as in MOOCs. The use of instructional strategies such as the Zone of Proximal Development can also help learners recognize their progression and thus reinforce their intrinsic motivation, known to be an important factor for student investment (Vygotsky, 1978).

Supporting learner's production of contents. All of the e-learning solutions in this review relied on a passive view of the learner, who receives information but does not produce content. For instance, we found no tool oriented toward writing activities among the solutions proposed, yet it is an essential skill used across all learning activities. Solutions addressing those specific activities could involve tools that help PWDs to take notes or to interact with other learners and instructors through forums and online chat, and consequently promote active learning. It is also important to consider the assessment part of online distance learning platforms (Admiraal, Huisman \& Pilli, 2015), especially when a peer assessment is used, as persons with cognitive impairments could have difficulties in judging open ended questions and could thus feel excluded from the learning community.

\subsection{Evaluation}

Progress in the e-learning field can be expected in terms of effectiveness assessment for people with cognitive impairment, notably in terms of evidence strength as well as in terms of solution generalization across the wide range of learning activities.

Design more robust evaluation methodology. As already stated, future studies should provide more robust methodology for the evaluation of accessibility solutions. Despite the fact that experimental protocols which rely on case studies can remain insightful when addressing end-users with such variability, it is really important to conduct studies using experimental control group protocols which 
compare the use of the proposed solution against a more traditional method. Future studies should also compare different solutions across a large spectrum of cognitive impairments to assess whether they are able to cope with the diversity of PWDs' situations. The comparison of two different solutions for the same learning activity should also help to identify the different possibilities that could be provided to the user. If lab studies are the first step in assessing the efficacy of the accessibility solutions proposed, evaluation should also take place in a real life environment during long-term studies to be as close as possible of the actual e-learning situation.

Evaluate the use of solutions to other relevant activities. Another interesting study of e-learning accessibility could be to investigate the relationship between proposed accessibility solutions and learning activities. Consequently, future studies should compare different solutions to determine which one is the most relevant for a specific learning activity. In addition, few different solution types are investigated, especially for the activities relevant to the Applying Knowledge category. Moreover, it is surprising that the more common solutions (e.g., use of game elements or accessible interfaces) are not used for all activities. For instance, gamification (Seaborn \& Fels, 2015) is already used for activities such as problem solving and decision making, and could be investigated to determine if it is relevant to use it to make such activities more accessible. Long-term studies should also investigate the daily life outcomes of accessible e-learning platforms by measuring the rate of employment of people with cognitive impairments who use them.

\section{Limitations}

This current systematic review has three main limitations. Similar to other reviews, the selection of the research keywords and the exclusion criteria was mostly subjective. However, the three authors participated in the final selection

process to ensure a reduction of bias. Secondly, as the systematic review relies on literature databases, it is not fully exhaustive: studies not referenced in 
the selected databases are not reviewed. However, we reduced the bias by choosing a set of databases covering the main disciplinary fields in which elearning accessibility might be addressed (computing, psychology and education sciences). Thirdly, as we decided to exclude summaries and books, we may have missed emerging trends that can represent more accurately the current state of research. Nevertheless, this choice has enabled us to highlight both the paucity of studies and a lack of maturity in the field concerning the scientific level of evidence. In future work, we recommend including a larger range of sources to provide more detailed results and examine accessibility solutions in the early stage of the research process.

\section{Conclusion}

The aim of our study was to contribute to laying the groundwork for a better understanding of online e-learning platform accessibility targeted at persons with cognitive impairments.

Four main conclusions can be formulated. Firstly, there is a paucity of studies that address the accessibility of e-learning for persons with cognitive impairments. Additionally, the studies available tend to focus more on design recommendations than on evaluating the effectiveness of e-learning systems.

Secondly, the use of accessibility standards is poor and generally inconsistent across the studies and they often lack rationalization in terms of their use in the design process.

Thirdly, there is a lack of special education references, with studies focusing more on specific neuropsychological disorders or syndromes (dyslexia, ADHD, etc.) rather than impairments of cognitive function (attention, memory, etc.) or learning activities as promoted by the ICF for fostering a profitable universal framework to study and act in favor of PWDs.

Finally, five categories of accessibility solutions (Adaptive systems, Gaming mechanics, Accessible content, Virtual agents and Accessible interfaces or environments) have been successfully extracted and associated with eight learning 
activities derived from the ICF.

The different results which emerged during the review process allowed us to identify promising directions for future research in this area and to make both design and evaluation research recommendations. A promising direction for research is to promote a multi-disciplinary approach combining educational sciences, cognitive sciences and computer science to develop e-learning systems that are both adaptable and adaptive. Such an approach will help to reinforce the relationship between accessibility or e-learning researchers, instructional designers, and direct and indirect end-users by giving them common references and thus help to provide solutions that fit every learner's situation.

\section{References}

Admiraal, W., Huisman, B., \& Pilli, O. (2015). Assessment in massive open online courses. Electronic Journal of E-learning, 13, 207-216.

Aist, G., Kort, B., Reilly, R., Mostow, J., Picard, R. et al. (2002). Experimentally augmenting an intelligent tutoring system with human-supplied capabilities: adding human-provided emotional scaffolding to an automated reading tutor that listens. In Proceedings of the 4th IEEE International Conference on Multimodal Interfaces (p. 483). IEEE Computer Society.

Alghabban, W. G., Salama, R. M., \& Altalhi, A. H. (2017). Mobile cloud computing: an effective multimodal interface tool for students with dyslexia. Computers in Human Behavior, 75, 160-166.

Andruseac, G. G., Rotariu, D., Rotariu, C., \& Costin, H. (2013). elearning platform for personalized therapy of learning disabilities. Procedia-Social and Behavioral Sciences, 83, 706-710.

Bakker, M., van den Heuvel-Panhuizen, M., \& Robitzsch, A. (2016). Effects of mathematics computer games on special education students' multiplicative reasoning ability. British Journal of Educational Technology, 47, 633-648. 
Barstow, C., \& Rothberg, M. (2004). Ims guidelines for developing accessible learning applications.

Battersby, S., Kelly, N., Brown, D. J., \& Powell, H. (2002). Online gardening to promote social inclusion. In International Conference on Computers for Handicapped Persons (pp. 150-152). Springer.

Beatty, J. (1982). Task-evoked pupillary responses, processing load, and the structure of processing resources. Psychological bulletin, 91, 276.

Benmarrakchi, F., El Kafi, J., \& Elhore, A. (2016). Supporting dyslexic's learning style preferences in adaptive virtual learning environment. In Engineering $\&$ MIS (ICEMIS), International Conference on (pp. 1-6). IEEE.

Burgstahler, S. (2009). Universal design of instruction (udi): Definition, principles, guidelines, and examples. DO-IT, .

Calvo, R., Arbiol, A., \& Iglesias, A. (2014). Are all chats suitable for learning purposes? a study of the required characteristics. Procedia Computer Science, 27, 251-260.

Calvo, R., Iglesias, A., \& Castaño, L. (2017). Evaluation of accessibility barriers and learning features in m-learning chat applications for users with disabilities. Universal Access in the Information Society, 16, 593-607.

Catarci, T., De Giovanni, L., Gabrielli, S., Kimani, S., \& Mirabella, V. (2008). Scaffolding the design of accessible elearning content: a user-centered approach and cognitive perspective. Cognitive processing, 9, 209-216.

Chatzara, K., Karagiannidis, C., \& Stamatis, D. (2016). Cognitive support embedded in self-regulated e-learning systems for students with special learning needs. Education and Information Technologies, 21, 283-299.

Clark, R. C., \& Mayer, R. E. (2016). E-learning and the science of instruction: Proven guidelines for consumers and designers of multimedia learning. John Wiley \& Sons. 
Clement, B., Oudeyer, P.-Y., \& Lopes, M. (2016). A comparison of automatic teaching strategies for heterogeneous student populations. In EDM 16-9th International Conference on Educational Data Mining.

Craik, F. I., \& Salthouse, T. A. (2011). The handbook of aging and cognition. Psychology Press.

Debevc, M., Verlič, M., Kosec, P., \& Stjepanovič, Z. (2007). How can hci factors improve accessibility of m-learning for persons with special needs? In International Conference on Universal Access in Human-Computer Interaction (pp. 539-548). Springer.

Dostál, J. (2015). Activating devices and their use in e-learning-focussed on handicapped students. Procedia-Social and Behavioral Sciences, 176, 284290.

Dyches, T. T., Smith, B. A., \& Syal, S. (2004). Redesigning an introduction to special education course by infusing technology. Computers in the Schools, 21, 59-72.

Fairclough, S. H. (2008). Fundamentals of physiological computing. Interacting with computers, 21, 133-145.

Fanou, S. (2009). Web 2.0: Engaging those with learning disabilities. In Proceedings of the 7 European Conference on e-Learning (354).(Reading, UK: Académie Publishing Limited).

Field, S., Sarver, M. D., \& Shaw, S. F. (2003). Self-determination: A key to success in postsecondary education for students with learning disabilities. Remedial and Special Education, 24, 339-349.

Friedman, M. G., \& Bryen, D. N. (2007). Web accessibility design recommendations for people with cognitive disabilities. Technology and Disability, 19, 205-212. 
Fryia, G. D., Wachowiak-Smolikova, R., \& Wachowiak, M. P. (2009). Web accessibility in the development of an e-learning system for individuals with cognitive and learning disabilities. In Networked Digital Technologies, 2009. NDT'09. First International Conference on (pp. 153-158). IEEE.

García, A. M., De Bra, P., Stash, N., Fletcher, G., Fabri, M., \& Pechenizkiy, M. (2016). Adaptive web-based educational application for autistic students. In CEUR Workshop Proceedings. volume 1628.

Gillespie, A., Best, C., \& O'Neill, B. (2012). Cognitive function and assistive technology for cognition: A systematic review. Journal of the International Neuropsychological Society, 18, 1-19.

González, A. M., \& Rodríguez, F. A. (2016). Enabling moocs' usage to mild and moderate intellectual disabled users: An approach to enhance mobile interfaces. User-Centered Design Strategies for Massive Open Online Courses (MOOCs), Hershey, PA: Information Science Reference, (pp. 157-175).

Harbour, R., \& Miller, J. (2001). A new system for grading recommendations in evidence based guidelines. BMJ: British Medical Journal, 323, 334.

Harrison, M., Stockton, C., \& Pearson, E. (2008). Inclusive, adaptive design for students with learning disabilities. In Advanced Learning Technologies, 2008. ICALT'08. Eighth IEEE International Conference on (pp. 1023-1027). IEEE.

Higbee, J. L., \& Goff, E. (2008). Pedagogy and student services for institutional transformation: Implementing universal design in higher education. Center for Research on Developmental Education and Urban Literacy, .

Hulusic, V., \& Pistoljevic, N. (2015). Read, play and learn: An interactive e-book for children with autism. In International Conference on Games and Learning Alliance (pp. 255-265). Springer. 
IMS Global Learning Consortium (2004). Ims accessforall meta-data overview, .

URL: http://www.imsglobal.org/accessibility/accmdv1p0/imsaccmd_ oviewv1p0.html.

Iniesto, F., McAndrew, P., Minocha, S., \& Coughlan, T. (2017). What are the expectations of disabled learners when participating in a mooc? In Proceedings of the Fourth (2017) ACM Conference on Learning@ Scale (pp. 225-228). ACM.

International Organization for Standardization (2016). 9999 assistive products for persons with disability-classification and terminology, . URL: https: //www.iso.org/obp/ui/\#iso:std:iso:9999:ed-6:v1:en.

Iradah, I. S., \& Rabiah, A. (2011). Edutism: an assistive educational system for the treatment of autism children with intelligent approach. In International Visual Informatics Conference (pp. 193-204). Springer.

Istenic Starcic, A., \& Bagon, S. (2014). Ict-supported learning for inclusion of people with special needs: Review of seven educational technology journals, 1970-2011. British Journal of Educational Technology, 45, 202-230.

Keefe, J. W. (1988). Profiling and Utilizing Learning Style. NASSP Learning Style Series.. ERIC.

Khowaja, K., \& Salim, S. S. (2013). A systematic review of strategies and computer-based intervention (cbi) for reading comprehension of children with autism. Research in Autism Spectrum Disorders, 7, 1111-1121.

Klimesch, W., Doppelmayr, M., Russegger, H., Pachinger, T., \& Schwaiger, J. (1998). Induced alpha band power changes in the human eeg and attention. Neuroscience letters, 244, 73-76.

Knight, V., McKissick, B. R., \& Saunders, A. (2013). A review of technologybased interventions to teach academic skills to students with autism spectrum disorder. Journal of autism and developmental disorders, 43, 2628-2648. 
Kolb, D. A. (1999). Learning style inventory: Version 3. Hay/McBer Training Resources Group.

Kurkovsky, S. (2009). Multimodality in mobile computing and mobile Devices: Methods for adaptable Usability: Methods for adaptable usability. IGI Global.

Liu, G.-Z., Wu, N.-W., \& Chen, Y.-W. (2013). Identifying emerging trends for implementing learning technology in special education: A state-of-the-art review of selected articles published in 2008-2012. Research in developmental disabilities, 34, 3618-3628.

Mendoza-Gonzalez, R. (2016). User-centered Design Strategies for Massive Open Online Courses (MOOCs). IGI Global.

Moher, D., Liberati, A., Tetzlaff, J., \& Altman, D. G. (2010). Preferred reporting items for systematic reviews and meta-analyses: the prisma statement. International journal of surgery, 8, 336-341.

Montero, F., López-Jaquero, V., Navarro, E., \& Sánchez, E. (2011). Computeraided relearning activity patterns for people with acquired brain injury. Computers \& Education, 57, 1149-1159.

Morales-Villaverde, L. M., Caro, K., Gotfrid, T., \& Kurniawan, S. (2016). Online learning system to help people with developmental disabilities reinforce basic skills. In Proceedings of the 18th International ACM SIGACCESS Conference on Computers and Accessibility (pp. 43-51). ACM.

Pearson, E. (2003). Designing a staff development course in inclusive design for online learning. International Journal on E-learning, 2, 52-59.

Perelmutter, B., McGregor, K. K., \& Gordon, K. R. (2017). Assistive technology interventions for adolescents and adults with learning disabilities: An evidence-based systematic review and meta-analysis. Computers $\mathscr{E}$ education, $114,139-163$. 
Peterson-Karlan, G. R. (2011). Technology to support writing by students with learning and academic disabilities: Recent research trends and findings. Assistive Technology Outcomes and Benefits, 7, 39-62.

Petz, A., \& Miesenberger, K. (2006). Ecdl bf: equal opportunities through equal access to an ecdl e-learning solution. In International Conference on Computers for Handicapped Persons (pp. 560-567). Springer.

Pirani, Z., \& Sasikumar, M. (2015). Assistive e-learning system for the learning disabled. Procedia Computer Science, 45, 718-727.

Rao, K., Edelen-Smith, P., \& Wailehua, C.-U. (2015). Universal design for online courses: applying principles to pedagogy. Open Learning: The Journal of Open, Distance and e-Learning, 30, 35-52.

Rello, L., Subirats, S., \& Bigham, J. P. (2016). An online chess game designed for people with dyslexia. In Proceedings of the 13th Web for All Conference (p. 28). ACM.

Roca, J. C., \& Gagné, M. (2008). Understanding e-learning continuance intention in the workplace: A self-determination theory perspective. Computers in human behavior, 24, 1585-1604.

Rose, D. H., \& Meyer, A. (2002). Teaching every student in the digital age: Universal design for learning.. ERIC.

Rossman, G. B., \& Rallis, S. F. (2003). Learning in the field: An introduction to qualitative research. Sage.

Ryan, R. M., \& Deci, E. L. (2000). Self-determination theory and the facilitation of intrinsic motivation, social development, and well-being. American psychologist, 55, 68 .

Sanchez-Gordon, S., \& Luján-Mora, S. (2016). Design, implementation and evaluation of moocs to improve inclusion of diverse learners. User-centered design strategies for massive open online courses (MOOCs), (pp. 115-141). 
Sanchez-Gordon, S., \& Luján-Mora, S. (2017). Research challenges in accessible moocs: a systematic literature review 2008-2016. Universal Access in the Information Society, (pp. 1-15).

Schelly, C. L., Davies, P. L., \& Spooner, C. L. (2011). Student perceptions of faculty implementation of universal design for learning. Journal of Postsecondary Education and Disability, 24, 17-30.

Scherer, M. J. (2005). Assessing the benefits of using assistive technologies and other supports for thinking, remembering and learning. Disability and rehabilitation, 27, 731-739.

Seaborn, K., \& Fels, D. I. (2015). Gamification in theory and action: A survey. International Journal of human-computer studies, 74, 14-31.

Sitra, O., Katsigiannakis, V., Karagiannidis, C., \& Mavropoulou, S. (2017). The effect of badges on the engagement of students with special educational needs: A case study. Education and Information Technologies, 22, 3037-3046.

Stipek, D. J. (1993). Motivation to learn: From theory to practice, .

Tandy, C., \& Meacham, M. (2009). Removing the barriers for students with disabilities: Accessible online and web-enhanced courses. Journal of Teaching in Social Work, 29, 313-328.

Tsiopela, D., \& Jimoyiannis, A. (2014). Pre-vocational skills laboratory: Development and investigation of a web-based environment for students with autism. Procedia Computer Science, 27, 207-217.

UN General Assembly (2007). Convention on the rights of persons with disabilities: resolution/adopted by the general assembly, 24 january 2007. A/Res/61/106 available at www. refworld/org. docid/45f97362html, .

Vygotsky, L. S. (1978). Mind in society: The development of higher mental process. 
Web Accessibility Initiative (2018). Web Accessibility Guidelines 2.1. Technical

Report. URL: https://www.w3.org/TR/WCAG21/.

Whyte, E. M., Smyth, J. M., \& Scherf, K. S. (2015). Designing serious game interventions for individuals with autism. Journal of autism and developmental disorders, 45, 3820-3831.

Wobbrock, J. O., Kane, S. K., Gajos, K. Z., Harada, S., \& Froehlich, J. (2011). Ability-based design: Concept, principles and examples. ACM Transactions on Accessible Computing (TACCESS), 3, 9.

World Health Organization (2001). International Classification of Functioning, Disability and Health: ICF.. World Health Organization.

World Health Organization (2011). World Report on Disability. Technical Report Genf, Schweiz. URL: http://bit.ly/2fAWg5J.

Xu, D., Huang, W. W., Wang, H., \& Heales, J. (2014). Enhancing e-learning effectiveness using an intelligent agent-supported personalized virtual learning environment: An empirical investigation. Information $\mathcal{E}$ Management, 51, 430-440.

Zimmerman, B. J. (2013). Theories of self-regulated learning and academic achievement: An overview and analysis. In Self-regulated learning and academic achievement (pp. 10-45). Routledge. 

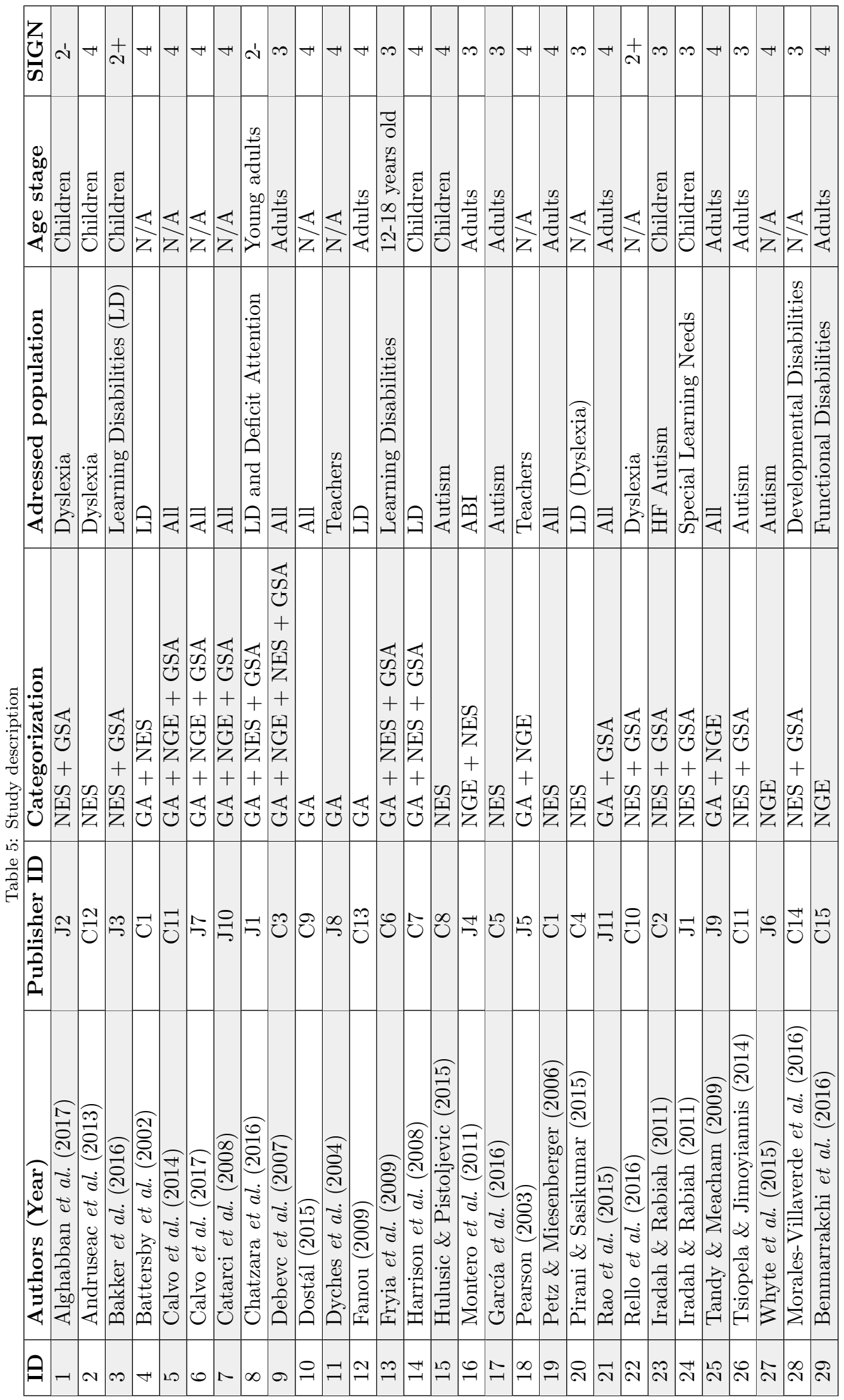